\title{
Os significados e as relações dos idosos com as drogas
}

\author{
Deivson Wendell da Costa Lima1 \\ Laryssa Dayanna Costa Ferreira² \\ Lucas Alves Ferreira ${ }^{3}$ \\ Lívia Dayane Sousa Azevedo ${ }^{4}$ \\ Margarita Antonia Villar Luis ${ }^{5}$ \\ Jaqueline Queiroz de Macedo ${ }^{6}$
}

Este estudo teve como objetivo compreender os significados que idosos atribuem ao uso de drogas. Pesquisa descritiva com abordagem qualitativa, realizada com idosos acompanhados por um Centro de Atenção Psicossocial Álcool e outras Drogas. Os dados foram produzidos através de entrevista semiestruturada e analisados conforme análise de conteúdo de Bardin. A droga surge como necessidade para a construção de vínculos ou para ocupar o vazio proporcionado pelas perdas afetivas. $\mathrm{O}$ uso dessas drogas desencadeia desgastes físicos e gera sofrimento psíquico, que determinam a busca por tratamento medicamentoso, religioso e psicossocial. Faz-se necessário um avanço na compreensão do uso de drogas para além da condição de dependência química dos idosos, considerando os significados desse uso e as vivências singulares dessas pessoas.

Descritores: Idoso; Drogas; Relações.

\footnotetext{
${ }^{1}$ MSc, Professor Assistente, Universidade do Estado do Rio Grande do Norte, Mossoró, RN, Brasil.

${ }^{2}$ Aluna do curso de Graduação em Enfermagem, Universidade do Estado do Rio Grande do Norte, Mossoró, RN, Brasil.

${ }^{3}$ Enfermeiro, Unidade Saúde da Família Bela Vista, Prefeitura Municipal de Assu, Assu, RN, Brasil.

${ }^{4}$ Nutricionista.

${ }^{5} \mathrm{PhD}$, Professor Titular, Escola de Enfermagem de Ribeirão Preto, Universidade de São Paulo, Centro Colaborador da OPAS/OMS para o Desenvolvimento da Pesquisa em Enfermagem, Ribeirão Preto, SP, Brasil.

${ }^{6}$ PhD, Professor, Departamento de Enfermagem Clinica, Universidade Federal da Paraíba, João Pessoa, PB, Brasil.
}

\author{
Correspondência: \\ Deivson Wendell da Costa Lima \\ Universidade do Estado do Rio Grande do Norte \\ Rua Dionísio Filgueira, 383, Centro \\ CEP: 59610-090, Mossoró, RN, Brasil \\ E-mail: deivsonwendell@hotmail.com
}




\section{The meaning and relations of elderly with drugs}

This study aims to understand the meanings the elderly attribute to drug use. This is descriptive qualitative research conducted with seven people monitored by the Psychosocial Care Center Alcohol and other Drugs. The information was collected through semi-structured interviews and analyzed according to Bardin's content analysis. The drug appears needed to build bonds or to fill the void created by affective losses. Drug use triggers physical strain and psychological suffering, leading to the search for medical, religious and psychosocial treatment. A breakthrough is necessary in understanding the use of drugs beyond dependency in the elderly, considering the meanings of such use and the unique experiences of these people.

Descriptors: Elderly; Drugs; Relations.

\section{Los significados y las relaciones de los ancianos con las drogas}

Este estudio tiene como objetivo comprender los significados que ancianos atribuyen al consumo de drogas. Investigación cualitativa descriptiva realizada con ancianos acompañado de un Centro de Atención Psicosocial de alcohol y otras drogas. Los datos fueron producidos utilizando entrevista semi-estructurada y analizados de acuerdo con Bardin. El droga como la necesidad surge para construcción de enlaces, para llenar el vacío proporcionado por pérdidas afectivas. El uso estos drogas provoca desgaste físico y genera sufrimiento mental, que determinan la búsqueda de tratamiento médico, religioso y psicosocial. Es necesario un gran avance la comprensión del uso de drogas, además de la condición de dependencia química de ancianos, teniendo los significados de la consumo y de las experiencias únicas de estas personas.

Descriptores: Anciano; Drogas; Relación.

Introdução

A população idosa cresce gradativamente no Brasil, com uma projeção para o ano de 2025 de 32 milhões de idosos, o que representará cerca de $15 \%$ do total da população brasileira ${ }^{(1)}$. Esses dados demandam profundas mudanças no âmbito social, familiar e ocupacional. Mudanças como aposentadoria, limitações físicas, perda de relacionamentos e solidão, podem implicar na vulnerabilidade para à intensificação do consumo de álcool e outras drogas ${ }^{(2)}$. O uso de drogas influencia diretamente o modo de viver e morrer do idoso e é determinante do seu processo de adoecimento, gerando aumento dos custos sociais e impactos nas diversas redes de atenção à saúde(3).
Apesar de que a quantidade de drogas consumidas seja maior na fase do jovem-adulto, existe a probabilidade do aumento de idosos usuários de drogas devido ao crescimento dessa população. Isto exige dos serviços de saúde novas abordagens e o uso terapêuticas que atendam as particularidades desta questão(4).

Acredita-se que esta problemática ainda não é abordada cotidianamente pelos serviços de saúde em função de que nesta faixa etária muitas pessoas não exercem atividades profissionais ou participam de atividades sociais, espaços que poderiam evidenciar as consequências do seu consumo de drogas. Outro fator é a falta de uma avaliação clínica que atenda às necessidades de saúde e sociais do idoso usuário de drogas, pois muitas vezes as consequências do uso das drogas são confundidas com os sintomas 
de doenças crônicas prevalentes nesta faixa etária. Concomitantemente, existe ainda a dificuldade por parte do idoso em falar sobre sua relação com a droga, a inexistência de qualificação profissional e o preconceito da família que nega o uso das drogas como um problema de saúde mental ${ }^{(3)}$.

O consumo de álcool e outras drogas entre idosos apresenta-se como um fenômeno complexo que é fortemente influenciado pelas relações singulares estabelecidas entre os idosos e essas substâncias de uso ao longo da vida. Face a esta problemática, este estudo tem como objetivo compreender os significados que idosos atribuem ao uso de drogas.

\section{Método}

Estudo qualitativo, de cunho descritivo. Teve como cenário o Centro de Atenção Psicossocial para Álcool e outras Drogas - CAPS AD III de município do interior do Rio Grande do Norte, serviço de referência para a região. Os sujeitos da pesquisa foram 07 idosos que, independentemente da(s) droga(s) da(s) qual(is) fazem ou fizeram uso, estavam sendo assistidos pelo serviço há mais de 3 meses.

Para coleta de dados foi realizada a entrevista semiestruturada. As entrevistas foram previamente agendadas de modo que se realizaram dois ou três encontros com cada idoso, com média de duração de 34 minutos, em local reservado, nas dependências da unidade de saúde. As falas dos sujeitos foram gravadas e transcritas. Para a análise dos dados empíricos foi utilizada a análise de conteúdo de Bardin que consiste em um conjunto de técnicas que têm por objetivo analisar as comunicações, utilizando-se de procedimentos (pré-análise, exploração do material e tratamento dos resultados e interpretação) sistemáticos de descrição dos conteúdos das mensagens ${ }^{(5)}$.

Este estudo foi previamente aprovado (CAAE $n^{\circ}$ 14566313.6.0000.5294) pelo Comitê de Ética em Pesquisa - CEP da Universidade do Estado do Rio Grande do Norte - UERN. Para garantir a preservação da identidade e organização dos depoimentos, os participantes foram identificados com a letra "l" de idoso, seguida de algarismo arábico.

\section{Resultados e discussão}

Identificou-se que os idosos atendidos pelo CAPS $A D$ eram do sexo masculino, com idade média de 65 anos, variando de 60 a 74 anos. Cinco idosos afirmaram que estavam separados ou divorciados e apenas dois relataram estar em um relacionamento (união estável). Com relação à ocupação três idosos relataram estar aposentados em consequência de comorbidades relacionadas ao uso do álcool e outras drogas. Quanto à escolaridade, quatro idosos apresentavam ensino fundamental incompleto e três não possuíam nenhum grau de instrução. No que se referem às drogas já consumidas, quatro idosos relataram uso exclusivo de álcool e três idosos disseram que fazem uso de álcool associado a outras drogas tais como o tabaco, psicotrópicos, maconha e crack.

A análise das entrevistas possibilitou a construção das seguintes categorias: justificativas para o uso de drogas, consequências geradas pelo uso da droga na vida do idoso e a busca por algum tipo de tratamento.

\section{Justificativas para o uso de drogas}

O primeiro uso da droga sofre influência direta do processo de interação sociocultural, havendo ocorrido na adolescência, idade adulta ou idosa. Os resultados mostraram como justificativas para o uso de drogas entre os idosos, a influência de pessoas próximas na infância e na adolescência e problemas psicossociais na fase adulta e idosa.

O uso de drogas pode surgir de forma associada à necessidade de uma identificação e partilha de experiências que são comuns a determinados grupos de indivíduos. De modo que a experiência do primeiro uso da droga sofre influência direta do processo de interação sociocultural entre os indivíduos que compõem um grupo(6).

Meu primeiro contato com o álcool foi com sete anos de idade, foi meu primeiro "porre". Foi devido a um tio meu, ele falou: "vá lá para casa que lá tem um tatu peba pra gente comer". Via o povo bebendo e comendo o tatu peba, queria experimentar, queria saber como é beber. Comecei a beber sempre quando estava com eles, foi um tio meu (I2).

Além disso, durante a infância as drogas estão presentes em momentos agradáveis, de festividades e comemorações em família, ocasionando seu uso recreacional e como forma de compor as relações sociais. Neste contexto, apresentam-se ainda os depoimentos de 11 e 14 que apontam o incentivo de familiares como fator desencadeante para o primeiro contato com a droga:

Foi por intermédio do meu pai e dos amigos dele sempre me chamavam. Um dia me chamaram para beber e eu caí na fraqueza. Comecei a achar bom e até hoje não parei não (I1).

Foi quando eu tinha uns 8 anos, meu tio que me chamou para beber. Na época a gente trabalhava e bebia, mas era só no fim de semana (14).

Assim, as drogas quando presentes no cotidiano familiar da criança e do adolescente tornam-se influenciadores da tomada de decisões a respeito do 
seu uso. Esse convívio familiar é capaz de interferir diretamente na maneira como a droga é vista nestas faixas etárias, ou seja, estas drogas podem ser percebidas como facilitadores da obtenção de prazer, diversão e inclusão social(7).

De outro modo, o início do uso de drogas ocorre por curiosidade, principalmente na fase da adolescência, como retrata o depoimento de 15. Meu avô me botava lá do lado de fora de casa e dava as costas para eu não ver ele tomar cachaça, só que eu era curioso. Eu tinha curiosidade de experimentar desde criança, mas só comecei a beber mesmo com meus amigos quando tinha 14 anos (I5).

No decorrer da vida o ser humano se depara com algumas situações que geram sentimentos adversos, ocasiões nas quais o sujeito pode recorrer ao uso de drogas ou intensificar seu consumo.

Perdi meu pai muito novo, eu tinha numa faixa dos 20 anos. Perdi meu pai e comecei a beber mais. Depois minha mulher morreu, comecei a beber o dobro mais. Eu enxergava no álcool como se fosse uma anestesia, que a pessoa está sofrendo uma dor. Está sofrendo uma dor e, através do álcool, eu via como uma anestesia, que aliviava aquele sofrimento que eu tinha pela perda do meu pai, mãe e esposa (I2).

Portanto, as drogas se apresentam como alternativa mais rápida e eficaz para lidar com algum tipo de sofrimento além de, supostamente, proporcionarem sentimentos de que a vida está sendo agradável e suportável(8).

De outra perspectiva, a relação da pessoa com as drogas interfere nos seus relacionamentos mais próximos, principalmente com cônjuges e filhos. Muitas vezes estes não conseguem lidar com situações conflituosas decorrentes do consumo das drogas, o que pode desencadear separações conjugais e o isolamento social. Consequentemente pode ocorrer um ciclo vicioso em que esse usuário intensifica o uso.

No tempo que eu comecei a beber mais foi porque minha mulher se separou de mim. Minhas filhas sempre reclamavam porque chegava em casa bêbado, a mulher brigava. [...] Com essa separação eu fiquei solitário e passei a beber todos os dias, porque eu sentia saudade dos meus filhos, eu sentia saudade do meu lar onde eu era casado e não podia voltar mais, devido à solidão eu ingressei no mundo do álcool (I1).

Outro exemplo pode ser a falta de um trabalho, conforme o relato de 14: Eu comecei a arrochar mesmo na cana depois dos meus 60 anos. Estava com desgosto porque eu trabalhava muito e hoje não posso mais trabalhar. Meti o pau no álcool, bebia todo dia. Eu botei na minha cabeça, sabe: eu vou beber até morrer (14).

O trabalho é uma atividade estruturante da vida humana, responsável pela construção da identidade e referencia social. No entanto, a ausência, a perda ou impossibilidade de exercer seu trabalho pode constitui-se em diversas implicações, dentre estas, ser um elemento condicionante para uso abusivo de drogas $^{(9)}$.

As sensações alcançadas através do contato com as drogas dependem das características de cada pessoa, e de suas expectativas em relação aos efeitos dessas substâncias.

\section{Consequências geradas pelo uso da droga na vida do idoso}

O uso do álcool e outras drogas pelos idosos acarretam problemas ao processo de envelhecimento como incapacidades para realizar suas atividades diárias, além do surgimento de doenças debilitantes. Além disso, o sofrimento psíquico do idoso que faz uso de drogas está relacionado com as perdas materiais, espirituais, de autoestima e danos familiares ${ }^{(4)}$. Nesse ínterim, as consequências expostas pelos participantes envolvem, principalmente, o desgaste físico e o sofrimento psíquico e familiar.

As consequências anatomofisiológicas decorrentes do uso de álcool e outras drogas são inegáveis. Tratando-se da população idosa, tais efeitos assumem proporção ainda mais relevante porque esta população apresenta uma redução do seu metabolismo hepático e da excreção renal(10)

Tive um começo de overdose, quase que eu morro. É uma dor insuportável, não me esqueço disso nunca e ataca aqui assim, ataca aqui no pulmão um pouquinho assim chega a região torácica. É uma dor insuportável, ela atacou aqui em mim, que eu fiquei ciscando no chão. A mulher do meu pai pegou e me botou num táxi e me levou para hospital (14).

Estas consequências são intensificadas principalmente para quem iniciou o uso ainda na infância ou na juventude, devido ao longo período de uso.

O álcool e o crack quase que me matavam. Tudo que eu consumia saia na urina, prejudicava minha respiração. No começo, eu não sentia nada, mas depois de um tempo adoeci. Começou a prejudicar o estômago, a bexiga, a boca, a garganta. Depois desses problemas de saúde, eu tentei parar e ir devagarzinho. Eu tenho que saber evitar (15).

Hoje, eu sou uma pessoa que tenho uma perda de memória. Hoje, eu vejo o estrago que a droga fez na minha vida.(17).

Tais relatos ressaltam que o consumo de drogas é um dos graves problemas de saúde da atualidade, devido às comorbidades, que contribuem para altos custos com tratamento médico e internação hospitalar, trazendo enorme repercussão social e econômica para a sociedade contemporânea(11).

Dentre os problemas de saúde e os riscos de doenças que as drogas podem gerar na vida do idoso 
tem-se as deficiências nutricionais e as alterações do padrão alimentar ${ }^{(12)}$.

Quando vim para cá, eu era bem magro, por causa da cachaça, hoje estou pesando bem mais, por que!? Devido a cachaça que deixei ne!? Por que eu não comia, de manhã já lavava a boca com cachaça, almoço era cachaça, janta era cachaça, merenda era cachaça, como é que uma pessoa dessa podia engordar!? Eu não ia engordar nunca [...] (12).

Alguns idosos relataram que faziam a substituição de refeições pelo álcool o que é considerado insuficiente para atender às suas demandas metabólicas; assim, a desnutrição se constitui em uma das consequências do uso do álcool. Dessa forma, quanto maior a participação do álcool na dieta, menor a densidade e qualidade nutricional da alimentação, o que ocasiona ao idoso a dificuldade de adquirir peso ideal e o surgimento de demais problemas alimentares ${ }^{(13)}$.

Além disso, o uso de bebidas alcoólicas associado a medicamentos prescritos para tratamento de suas doenças podem provocar maiores desgastes físicos e interferir no respectivo tratamento(14).

Hoje em dia eu sou aposentado, tomo remédio controlado, tenho diabetes agora, tomo remédio para diabetes também. Por causa de tudo isso não paro de beber, as vezes paro, fica só na lembrança (I7).

O uso do álcool pode aumentar os níveis de glicemia e alterar o controle metabólico, bem como um longo tempo do uso do álcool aumenta o risco de desenvolver hipertensão $\operatorname{arterial(15)~}^{(15)}$

Chegou um tempo que não tinha mais condições, não tinha como trabalhar, porque o álcool modificou minha vida [...] eu não tenho mais condições de trabalhar, quando eu trabalhava eu ficava tonto, com pressão alta, minha pressão já chegou a 21/13mmHg, quase que me dava um troço (I1).

Aquele que faz uso do álcool possui mais susceptibilidade para atrasos no trabalho, queda da produtividade, para a ocorrência de acidentes e de conflitos; muitas vezes o idoso é demitido ou é obrigado a abandonar o trabalho(9).

Além dos desgastes físicos, o uso prolongado do álcool e de outras drogas pelo idoso pode gerar consequências em diversas esferas da vida do sujeito, ocasionando perdas emocionais e sociais, sofrimento psíquico para ele e sua família, conforme relata 14:

Eu perdi a mulher por causa de bebida. Hoje em dia eu moro sozinho e Deus, num quartinho alugado (14).

A relação do idoso com o álcool pode dificultar as relações sociais e afetivas e muitas vezes resulta em dificuldades para estabelecer vínculos mais sólidos e permanentes $^{(16)}$

Quando algum membro familiar faz uso de álcool ou de outra droga, a família experimenta situações que podem alterar sua rotina, o que pode dificultar ainda mais sua convivência; pois, ele passa a valorizar mais a sua relação com a droga do que as pessoas com quem convive(8).

Perdi minha família, se afastaram que eu acho que foi por causa da bebida, não tenho muita relação com o pessoal da família também (I2).

Ao longo da vida, alguns idosos vivenciam perdas familiares, sociais e subjetivas que impossibilitaram atingir seus sonhos. Estas perdas podem produzir o desinteresse pela vida e a escolha do suicídio como forma de escapar do intenso sofrimento(17).

Por que eu estava com desgosto da vida, sozinho, sem ninguém, mas doido eu não era não. Já tinha tentado morrer por que não queria mais viver, viver pra que!? (14).

Idosos, especialmente homens e pessoas com história de uso de álcool e outras drogas são consideradas umas das populações de risco para o suicídio. Muitas vezes, as drogas são usadas como fuga ou minimização dos sintomas de doenças e estabelecem relação direta com situações recentes que impulsionam a tentativa do suicídio ou autoextermínio(18).

\section{A busca por algum tipo de tratamento}

Em geral o tratamento para o usuário de drogas caracteriza-se pela oferta de terapêuticas pautadas no uso de medicamentos, que em muitos casos também são associados às práticas religiosas. Outras abordagens como a atuação multiprofissional, as redes de atenção e a busca por apoio familiar também são empregadas. Em cada tratamento pode existir mais de um tipo de abordagem onde em geral uma influencia a outra.

Nessa categoria, foram consideradas as abordagens de tratamento descritas pelos nossos entrevistados, de modo que emergiram a abordagem medicamentosa, a religiosa e a psicossocial.

O tratamento medicamentoso é a abordagem prioritária das intervenções médicos-psiquiátricas, onde a centralidade do discurso científico coloca o saber psiquiátrico como regente das prescrições e diagnósticos voltados para o idoso usuário ${ }^{(19)}$.

Aqui eu passo pelo médico todo mês, só assim me dão os remédios. Eu tomo os remédios, tomo comprimido para dormir, comprimido para dor, porque às vezes doí muito, tudo isso por causa do tanto que bebi (17).

Os medicamentos instituíram-se como recurso terapêutico exclusivo e prioritário para o idoso lidar com os problemas advindos do uso abusivo das drogas.

Quando eu tomo comprimido eu não posso mais beber. Eu tomo comprimido, ai eu vou comer. Pronto. Passa a vontade de usar. Pego meus comprimidos aqui, através destes comprimidos eu já estou diminuindo [...] (16). 
Esse comprimido de vez em quando é que tira meu pensamento, mas meu pensamento para ir lá em tromba e voltar. Eu tomo os comprimidos, os comprimidos ligeiramente tiram o negócio da minha cabeça que eu estou pensando, tiram essa vontade de querer a droga (17).

16 afirma que ocorre uma possível substituição da droga de uso pelo medicamento receitado e 17 relata que sente a necessidade de utilizar o comprimido quando passa pelos sintomas de abstinência da droga. Neste sentido, considera-se que o medicamento se constitui como uma forma de lidar com o abuso de drogas, mas seu uso envolve riscos, entre os quais está o de reduzir as perspectivas de tratamento ao sentido farmacológico, substituindo o consumo de uma droga pelo uso de outra.

Alguns idosos relataram o uso de medicamentos considerados por eles como sendo mais fortes, durante os períodos de internação em hospitais psiquiátricos.

Lá eu recebia meu tratamento, os médicos me passavam remédios fortes. As internações variavam às vezes eu ficava 30, 40, 45 dias, dependia do meu comportamento, quando eu começava a engordar e ficar melhor eu tinha alta, mas voltava de novo. O álcool tem me destruído, não consigo trabalhar, não consigo mais fazer nada direito. Eu tive 106 entradas no hospital psiquiátrico. As pessoas se afastam quando falo que dei entrada naquele lugar (I6).

As recorrentes internações relatadas pelo idoso nos hospitais psiquiátricos demonstram a insuficiência deste tipo de tratamento, que é marcado pelo preconceito e exclusão. Sob a lógica da Reforma Psiquiátrica, na atenção à crise e às urgências relacionadas ao uso de drogas, a internação psiquiátrica é considerada um tratamento de exceção que deve ser acionada apenas quando todos os outros recursos terapêuticos da rede de atenção psicossocial forem esgotados. É essencial que seja feita uma avaliação criteriosa da internação, baseada na história de vida do idoso e da sua relação com a droga, na perspectiva de garantir a continuidade do tratamento nos serviços de atendimento comunitário, com fortalecimento da rede de apoio social e dos laços familiares ${ }^{(20)}$.

A prática religiosa aparece como um fator potencial de proteção para o consumo de drogas uma vez que pode proporcionar um sentimento de fortalecimento pessoal, um maior envolvimento nas relações sociais e a construção de alternativas para solucionar os problemas vivenciados no dia a dia(21).

Os relatos apontam que os idosos acreditam que a prática do rezar e o suporte fornecido pela fé permitem uma renovação espiritual e diminuição do seu sofrimento pelo abuso de drogas.

Toda vida eu peço muito a Deus, sempre busco por Deus e Deus faz a parte Dele, mas só que eu não estou fazendo a minha parte. Atualmente, agora, eu tive uma recaída pesada, mas toda vida quando eu precisava Dele, Ele me ajuda, me protege e eu vou indo (I3).

Nesse sentido, a dimensão religiosa assume uma função de reconfiguração das relações sociais e familiares afetando, assim, os padrões de uso de álcool e outras drogas ${ }^{(21)}$. Todavia, percebe-se que os idosos entendem o suporte religioso como uma força ativa que os retirará da prática de abuso de drogas.

Eu quero que Deus me dê o bom ar, minha vida liberta das drogas, isso é o que eu digo a meu Deus todo dia 24 horas. Eu levanto de 3 horas da manhã para orar, me ajoelho, choro. Eu peço a Deus que me recupere, que eu não tente mais tirar minha vida por causa de drogas, é o que eu peço a Ele, Pai me ajude, eu estou precisando, eu estou necessitado. O Senhor é o meu Pai, me ajuda! Eu peço isso a Ele todo dia (I2).

Nesse discurso, o idoso apresenta alguns símbolos e expressa valores que caracterizam a religiosidade, é o caso das orações, da penitência de se ajoelhar diante de Deus. Além disso, cabe destacar as súplicas realizadas pelo idoso em busca urgente de ajuda espiritual. Observa-se, que diante da impotência que sente em mudar seu comportamento, a busca por algo que acredita ser superior a ele é uma fonte de alento e coragem diante do desejo de utilizar drogas. Desse modo é de se compreender por que em muitas situações a religiosidade aparece como fator de proteção para o suicídio, uso de álcool e outras drogas e sofrimento psíquico(22).

A abordagem de tratamento psicossocial tem como objetivo minimizar o sofrimento das pessoas devido as consequências do uso das drogas, bem como sensibilizá-las por melhoria da qualidade de vida, indo além do tratamento de desintoxicação e de abstinência. No Brasil estas abordagens tornaram-se possíveis a partir da Lei 10.216/2001 que assegura o direito das pessoas em sofrimento psíquico, e dispõe sobre a construção de uma rede de saúde mental comunitária substitutiva ao modelo manicomial(23).

Dentre estes serviços de saúde, tem-se o Centro de Atenção Psicossocial de Álcool e outras Drogas 24h - CAPS AD III, que assume um papel estratégico na organização da rede comunitária de cuidados as pessoas com necessidades relacionadas ao consumo de álcool, crack e outras drogas ${ }^{(10)}$. Esse serviço é mencionado pelos idosos como um dos recursos de tratamento aos problemas advindos do uso de drogas:

Eu procurei o CAPS AD III, porque quando eu estou no CAPS eu passo muito tempo sem beber. Eu procurei aqui porque senão eu ia morrer (I3).

Cada idoso percorreu diversos serviços de saúde em busca de cuidados relacionados as consequências 
pelo uso das drogas. Ao chegar no CAPS AD III, este tornou-se um local de proteção e segurança. Isso coloca grandes desafios aos profissionais deste serviço, na construção de atividades terapêuticas capazes de conciliar a singularidade dos idosos e o impacto coletivo das intervenções.

Eu gosto das atividades em grupo do CAPS AD III. Gosto de aprender, aprendemos a ler, escrever, faço algumas atividades, levo para casa. Tem algumas palestras também, conversas, dança, tem muita gente também, eu gosto das pessoas daqui. Já faz 8 anos que eu estou aqui, venho quase todo dia (14)

Além disso, 16 relaciona o seu processo de tratamento ao vínculo estabelecido com os profissionais do CAPS AD III e aponta a confiança por parte dos funcionários como elemento importante:

Procurei o CAPS porque aqui no CAPS eles fazem a diferença, tem os funcionários, me ajudam bastante, confiando em mim, porque o meu defeito é só a bebida (16).

Uma abordagem terapêutica da pessoa que usa drogas precisa estar voltada para a singularidade de cada caso, baseando-se na liberdade, no respeito e na corresponsabilidade daquele que está sendo tratado, de modo que o estabelecimento de vínculos sejam fortalecidos juntos à sua família e sua comunidade ${ }^{(20)}$.

A participação dos idosos nos grupos é o momento de socialização, de aprendizagem e de lazer. Os grupos facilitam a produção coletiva do conhecimento, pois é um espaço de criação de vínculos e de reflexão acerca das situações de vida ${ }^{(24)}$

Eu procurei o CAPS e criei uma família que eu não tive. Aqui tenho conversa, atividades, eu tenho meu apoio. Aqui é bom quando a gente participa do grupo, a gente desabafa, por que quando eu desabafo eu fico assim bem leve, quando eu não desabafo eu fico no meu canto sozinho (I5).

Nesse sentido, o grupo é entendido como um espaço de escuta, discussão, compartilhamento de experiências e, por isso, um espaço rico de interação e formação de vínculos ${ }^{(24)}$. Outro aspecto importante refere-se ao acompanhamento do idoso pela família neste serviço:

A família é tudo, meu suporte [...] se eu não tivesse tomado a atitude de procurar a família, para pedir ajuda, eu tinha me acabado nessa vida ruim, não aguentava mais ficar sozinho. Eles me ajudam muito para vir para cá (I5)

A família não deve apenas acompanhar a pessoa que faz uso de drogas ao serviço de saúde, mas se envolver mais no cuidado realizado ao idoso demonstrando zelo, apoio e afeto. Além disso, torna-se necessário ainda o acolhimento e o tratamento também dos familiares, no intuito de estreitar os seus laços, minimizar a sobrecarga emocional e reorganizar as funções familiares ${ }^{(11)}$.

\section{Conclusão}

Existem diferentes significados atribuídos ao consumo das drogas por idosos, sendo destacados o uso de uma droga como um mecanismo de fuga utilizado para minimizar sofrimentos e aliviar as perdas. Como uma busca por novas experiências de vida despertadas a partir do estabelecimento de novas formas de usar a droga, e ainda como objetos de desejo pelos idosos, uma vez que a curiosidade e a vontade de fazer o uso dessas substâncias apresentam-se de forma marcante nas falas dos entrevistados.

Esta pesquisa traz sua contribuição ao propor a discussão do uso de álcool e outras drogas a partir da fala do idoso, demonstrando um avanço na compreensão do uso de substâncias psicoativas para além da condição de dependência química e que podem orientar a formulação de estratégias de cuidado adequadas através de planos terapêuticos individuais.

Vale ressaltar que esta pesquisa apresenta limitações, na medida em que retrata a realidade de uma única instituição, o que aponta para a necessidade de mais pesquisas nessa linha, em outras realidades, com vistas à complementaridade da construção de um conhecimento relevante para a efetivação do cuidado integral aos idosos que fazem uso de álcool e outras drogas.

\section{Referências}

1. Instituto Brasileiro de Geografia e Estatística (IBGE). Síntese de Indicadores Sociais: uma análise das condições de vida da população brasileira. Rio de Janeiro: IBGE; 2012.

2. Ottoni MAM. Longevidade: Uma Conquista ou um Peso para a Sociedade Brasileira?. Polêmica. 2014 jan-fev; 13(1):996-1005.

3. Kano MY, Santos MA, Pillon SC. Use of alcohol in the elderly: transcultural validation of the Michigan Alcoholism Screening Test - Geriatric Version (MAST-G). Rev Esc Enferm USP. 2014; 48(4): 649-55.

4. Wallace $C$, Black DJ, Fothergill A. Integrated assessment of older adults who misuse alcohol. Nurs. Stand. 2010; 24(33): 51-7.

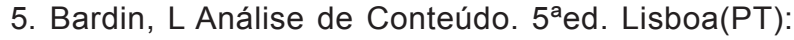
Edições 70; 2009.

6. Kuerbis A, Sacco P, Blazer DG, Moore AA. Substance Abuse Among Older Adults. Clinics in geriatric medicine. 2014;30(3):629-654.

7. Silva SED, Padilha MI. Alcoholism in adolescents' life histories: an analysis in the light of social representations. Texto Contexto Enferm. 2013 set; 22 (3): 576-84.

8. Neves ACL, Miasso Al. "Uma força que atrai:" o significado das drogas para usuários de uma ilha de 
cabo verde. Rev Latino-Am Enfermagem. 2010 mai-jun; 18(Spec): 589-97.

9. Beck LM, David HMSL. Drug abuse and workplace: possibilities to nurse actuation. Esc. Anna Nery. 2007; 11(4):706-11.

10. Ministério da Justiça (Brasil). Secretaria Nacional de Políticas sobre Drogas. Tratamento da dependência de crack, álcool e outras drogas: aperfeiçoamento para profissionais de saúde e assistência social / Supervisão Técnica e Científica Paulina do Carmo Arruda Vieira Duarte - SENAD. Responsáveis Técnicos Lísia Von Diemen, Silvia Chwartzmann Halpern e Flavio Pechansky - UFRGS. Brasília:SENAD; 2012. 248p.

11. Medeiros KT, Maciel SC, Sousa PF, Souza FMT, Dias CCV. Representações sociais do uso e abuso de drogas entre familiares de usuários. Psicol. estud. 2013; 18(2): 269-79.

12. Cruz ACM, Leite FC, Sousa JBG. O uso do álcool e suas consequências na saúde dos consumidores. Revista FAMA de Ciências da Saúde. 2015; 1(2): 11-18.

13. Senger AEV, Ely LS, Gandolfi T, Schneider RH, Gomes I, Carli GA. Alcoolismo e tabagismo em idosos: relação com ingestão alimentar e aspectos socioeconômicos. 2011; 14(4):713-19.

14. Martins KD. A dependência do álcool na dialética do envelhecimento. Revista Conteúdo. 2014 set-dez; $7(1): 32-45$.

15. Olivatto GM, Veras VS, Zanetti GG, Zanetti ACG, Ruiz FGR, Teixeira CRS. Consumo de álcool e os resultados no controle metabólico em indivíduos com diabetes, antes e após a participação em um processo educativo. SMAD, Rev. Eletrônica Saúde Mental Álcool Drog. 2014;10(1):3-10. 16. Ribeiro DB, Terra MG, Soccol KLS, Schneider JF, Camillo LA, Plein FAS. Motivos da tentativa de suicídio expressos por homens usuários de álcool e outras drogas. Rev. Gaúcha Enferm. 2016 mar; 37 (1).

17. Sousa GS, Silva RM, Figueiredo AEB, Minayo MCS, Vieira LJES. Circunstâncias que envolvem o suicídio de pessoas idosas. Interface (Botucatu). 2014 mar; 18(49):389-402.

18. World Health Organization (WHO). Preventing suicide: a global imperative. Geneva: WHO; 2014.

19. Guarido R. A medicalização do sofrimento psíquico: considerações sobre o discurso psiquiátrico e seus efeitos na Educação. Educ. Pesqui. 2007; 33(1):151-61.

20. Zeferino MT. Crise e Urgência em Saúde Mental: o cuidado às pessoas em situações de crise e urgência na perspectiva da atenção psicossocial / Maria Terezinha Zeferino, Jeferson Rodrigues, Jaqueline Tavares de Assis (orgs.). - Florianópolis (SC): Universidade Federal de Santa Catarina, 2014. 180 p.

21. Faria MGA, David HMSL, Rocha PR. Inserção e prática religiosa entre mulheres: Aspectos protetores ao uso de álcool e violência. SMAD, Rev. Eletrônica Saúde Mental Álcool Drog. 2011; 7(1): 32-37.

22. Melo CF, Sampaio IS, Souza DLA, Pinto NS. Correlação entre religiosidade, espiritualidade e qualidade de vida: uma revisão de literatura. Estud Pesqui Psicol. 2015;15(2):447-64.

23. Pinho $\mathrm{PH}$, Oliveira MA, Almeida MM. A reabilitação psicossocial na atenção aos transtornos associados ao consumo de álcool e outras drogas: uma estratégia possível?. Rev. psiquiatr. clín. 2008; 35(1):82-8.

24. Santos LF, Oliveira LMAC, Munari DB, Peixoto MKAV, Barbosa MA. Therapeutic factors in group support from the perspective of the coordinators and group members. Acta Paul Enferm. 2012;25(1):122-27. 